\title{
The Process of Management and Control of Feasibility Planning of Road Construction Using the Financial Information System
}

\author{
Gulnara A. Gareeva ${ }^{1}$, Diana R. Grigoreva ${ }^{1} \&$ Ilnur I. Mahmutov ${ }^{1}$ \\ ${ }^{1}$ Department of Economics of Enterprises and Organizations, Faculty of Economics, Nabereznye Chelny, Kazan \\ Federal University, Kazan, Russia \\ Correspondence: Gulnara A. Gareeva, Department of Economics of Enterprises and Organizations, Faculty of \\ Economics, Nabereznye Chelny, Kazan, Russia. E-mail: gagareeva1977@mail.ru
}

Received: September 2, 2020

Accepted: October 20, 2020

Online Published: December 24, 2020

doi:10.5430/ijfr.v12n1p184

URL: https://doi.org/10.5430/ijfr.v12n1p184

\begin{abstract}
Technical and economic planning control and effective organization of management processes in current situations are particularly significant. This is essential to automate orders and handle them effectively. Hence, the solution of tasks associated with planning, accounting, and distribution of orders is of great practical significance. The financial information system that operates at the enterprise does not allow sufficient automation of the enterprise's work and divisions. Analysis of the information system has revealed that automation of document flow and information flows of employees of the "planning and economic Department" is inadequate.

Consequently, research objects are the business process - "Technical and economic planning" and the task "Distribution of orders by teams." The subsystem «Technical and economic planning» was produced, indicating the subsystem's tasks and the functions of the tasks. A connection diagram was composed of the tasks of this subsystem with the tasks of other subsystems. The task «Distribution of orders by teams» was expanded and implemented as a software product in the 1C programming environment. The chief issues of ensuring the information security of enterprises and the direction of forming a system of protection of information resources, particularly of limited access resources, are considered. The effectiveness of the implementation of the task "Distribution of orders by teams" were assessed: the annual economic effect of the implementation amounted to 2237, 03 rub.; the cost of developing a software product $-25715,40$ rub.; discounted payback period is 11 months.
\end{abstract}

Keywords: information system, business processes, design, technical and economic planning, reengineering of business processes

\section{Introduction}

Organizations currently produce and accumulate vast amounts of data, such as orders. They, in turn, need fast processing and high-quality storage. For this purpose, enterprises use standard information systems aimed at solving problems of automation of accounting and enterprise management. But increasingly, standard information systems need to be refined and improved (Falko \& Berzin, 2012).

To date, the problem of implementing and improving the software product "1C: Enterprise 8.2"is relevant for the company.

The purpose of the study is to achieve economic and managerial efficiency in the construction industry with the use of modern information technologies. The problem-oriented approach to the implementation of information systems allows us to present the company's activities as a set of business processes (Ivanov \& Zyablov, 2013). This approach ensures information integrity. This allows you to increase the speed of transmitting operational information, maintain a high level of data reliability, improve the quality of data processing and optimize the effectiveness of decisions (Radchenko, 2013).

\section{Methods}

Business process reengineering is a radical redesign of business processes of enterprises to achieve sharp, spasmodic improvements in the main indicators of their activity: cost, quality, services and pace. It is aimed at ensuring that not only every link in the business is productive, but also that the entire system of their interaction strives to obtain the maximum effect of animation. 
The reengineering process can be divided into stages:

1. The desired image of the company is formed, which occurs as part of the development of the strategy of the company, its main guidelines and ways to achieve them. Of particular importance in a number of strategic goals is customer orientation.

2. A model of the real or existing business of the company is created. This stage is called retrospective, or reverses, reengineering. Here, the system of actions and works is recreated, with the help of which the company realizes its existing goals. A detailed description and documentation of the main operations of the company is made, their effectiveness is evaluated. To create a model of an existing business, the results of the analysis of the organizational environment and controlling data are used. The processes in need of fundamental restructuring are determined.

3. A new business model is being developed. There is a redesign of the current business - direct reengineering of business processes.

In the process of reengineering, the following business processes are identified:

Preparation for production, The main production, Logistics, Finance, Accounting, Transport support, Repair support, Staffing, Social security, Provision of core business, Information support, Management (management).

Based on business processes, an analysis of the structural divisions of the enterprise information system is made. List of enterprise subsystems: Subsystem «Technical and economic planning»; The subsystem «Main production»; The subsystem «Logistics»; Subsystem «Accounting»; Subsystem «Finance»; Subsystem «Transport support»; Subsystem «Repair support»; Subsystem «Provision of labor resources»; Subsystem «Provision of core business».

An economic information system is a system whose functioning over time consists in collecting, storing, processing and disseminating information about the activities of an economic object in the real world. The widespread use of technical means of processing and transmitting data in all spheres of the life of society leads to the fact that minor malfunctions in the work of the built-up technological chain often become the main cause of large information losses for the enterprise (Lisin, \& Faizullin, 2013).

Tasks to be automated:

1. Subsystem «Production Preparation»:

1.1. Subsystem «Technical and Economic Planning»:

1.1.1 Drawing up a schedule of construction and repair work;

1.1.2 Distribution of orders by teams;

1.1.3 Formation of the composition and scope of preparatory work;

1.1.4 Formation of a schedule for the preparation of production;

1.1.5 Control, regulation of production preparation;

2. The subsystem «Main production»:

2.1.1 Calculation of capacity utilization;

2.1.3 Calculation of the actual fund of working time;

2.1.4 Formation of production tasks (orders);

2.1.6 Control of marriage, accidents, organizational downtime;

2.1.8 Assessment of the quality of reservoir studies.

5. Subsystem «Finance»:

5.1.2 Budgeting. Estimation of income and expenses;

5.1.3 Analysis of the implementation of plans for parties and detachments;

5.1.5 Forecasting economic activity;

5.1.6 Control over the timely receipt of funds;

6. Subsystem «Transport support»:

6.1.2. Repair planning;

6.1.3. Formation of applications for the purchase of spare parts; 


\subsubsection{Planning transport updates;}

6.1.5. Control of actual transportation;

6.1.6. Control processing of waybills.

\section{Repair support:}

7.1.1. Calculation of the cost of repair and maintenance of the site;

7.1.2. Calculation of the need for materials;

7.1.3. Formation of applications for the supply of equipment;

7.1.5. Formation of orders for maintenance and repair;

7.1.6. Analysis of the work performed;

7.1.7. Control of the movement of equipment, machinery, materials;

7.1.8. Monitoring the preparation of the site for operation;

9. Provision of core business:

9.1.1. Ensuring the safety and security of life of the enterprise;

9.1.2. Monitoring the availability of personal protective equipment;

9.1.3. Carrying out measures to prevent industrial accidents;

\subsubsection{Legal support, compliance with legal regulations.}

The subsystem of technical and economic planning receives information about orders for construction and repair work. These orders are recorded and entered in the table «Orders» (Barsukov, 1997).

Construction work on the road is carried out by the team, which is the main production unit of road construction enterprises. The team can perform all construction work or specialize in certain types of construction and repair work. Depending on the type of work, the teams are divided into procurement, perforating, assembly, technological design teams, etc. The team has mobile roadside installations, a cable lift, geodetic and ground equipment, and other means necessary for carrying out the work (Grigorevaet al., 2015).

Orders are accepted by telephone. The dispatcher accepting the order must accurately enter the data on the order (road number, type of work, date of acceptance of the order, date of completion of the order). After that, he finds in the directory the numbers of the brigades that perform these types of work, clarifies the payroll of the team, and by the type of work he finds the cost of this order. After all that has been done, the dispatcher fills out an act-outfit for work. The dispatcher must confirm it within 2 hours after accepting the order (Gareeva, 2016)

The results of the task: Distribution of orders by teams; Accounting for the list of teams; Accounting for the value of the order; Elimination of errors in the distribution of the order; Accounting for the performance of work. To develop the task, the configuration capabilities of 1C: Enterprise 8.2 was used. The algorithm for solving the problem is shown in Figure 1.

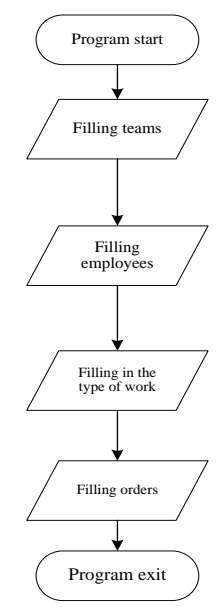

Figure 1. Algorithm for implementing a software product 
Software development costs are presented in Table 1.

Table 1. Estimated cost of software development

\begin{tabular}{|c|c|c|c|}
\hline Naming of expenditures & Before implementation & After implementation & Amount of savings \\
\hline \multicolumn{4}{|l|}{ 1.Naming of expenditures } \\
\hline labor costs & 900,00 & 30,00 & 870,00 \\
\hline accountant & 1875,00 & 225,00 & 1650,00 \\
\hline economist & 721,50 & 66,30 & 655,20 \\
\hline \multicolumn{4}{|l|}{ 2. social security contributions } \\
\hline \multicolumn{4}{|l|}{ 3. depreciation of fixed assets } \\
\hline software & 37,81 & 2,10 & 35,71 \\
\hline building & 14,38 & 0,80 & 13,58 \\
\hline office equipment & 32,93 & 2,74 & 30,19 \\
\hline \multicolumn{4}{|l|}{ 4. other } \\
\hline communication services & 26,67 & 26,67 & 0,00 \\
\hline electric power & 21,80 & 2,33 & 19,47 \\
\hline paper & 3,90 & 1,82 & 2,08 \\
\hline $\begin{array}{l}\text { total cost of solving a business } \\
\text { problem }\end{array}$ & 3633,99 & 357,76 & 3276,23 \\
\hline
\end{tabular}

Table 2 presents data on the costs of solving a business problem without using software.

Table 2. Estimated cost of solving a business problem without using software

\begin{tabular}{|c|c|c|c|}
\hline Naming of expenditures & consumption rate / laboriousness & $\begin{array}{l}\text { unit price / the cost of } \\
\text { normo hours }\end{array}$ & amount \\
\hline \multicolumn{4}{|l|}{ 1.labor costs } \\
\hline accountant & person / hour & 60 & 900 \\
\hline economist & person / hour & 75 & 1875 \\
\hline 2. social security contributions & & & 721,5 \\
\hline \multicolumn{4}{|l|}{ 3. depreciation of fixed assets } \\
\hline software & 0,0016 & 23000 & 37,81 \\
\hline building & & & 14,38 \\
\hline office equipment & 0,00110 & & 32,93 \\
\hline \multicolumn{4}{|l|}{ other } \\
\hline communication services & day & 13,33 & 26,67 \\
\hline electric power & $\mathrm{Kv} / \mathrm{h}$ & 2 & 21,8 \\
\hline paper & pack & 130 & 3,9 \\
\hline Total cost of solving a business & & & 3633,99 \\
\hline
\end{tabular}

Table 3 presents the data on the costs of solving a business problem using software. 
Table 3. Estimated cost of solving a business problem using software

\begin{tabular}{|c|c|c|c|}
\hline Naming of expenditures & consumption rate / laboriousness & $\begin{array}{l}\text { unit price / the cost of } \\
\text { normo hours }\end{array}$ & amount \\
\hline \multicolumn{4}{|l|}{ 1.labor costs } \\
\hline accountant & person / hour & 60 & 30,00 \\
\hline economist & person / hour & 75 & 225,00 \\
\hline 2. social security contributions & & & 66,30 \\
\hline \multicolumn{4}{|l|}{ 3. depreciation of fixed assets } \\
\hline software & 0,00009 & 23000 & 2,10 \\
\hline building & & & 0,60 \\
\hline office equipment & 0,00009 & 30050 & 2,74 \\
\hline \multicolumn{4}{|l|}{ other } \\
\hline communication services & day & 13,33 & 26,67 \\
\hline electric power & 1,165 & 2 & 2,33 \\
\hline paper & 0,014 & 130 & 1,82 \\
\hline Total cost of solving a business problem & & & 357,56 \\
\hline
\end{tabular}

Table 4 shows the amount of cost savings after the implementation of software.

Table 4. Savings after the implementation of software

\begin{tabular}{llll}
\hline Naming of expenditures & Before implementation & After implementation & Amount of savings \\
\hline $\begin{array}{lll}\text { 1.labor costs } \\
\text { accountant }\end{array}$ & 900 & 30 & 870 \\
\hline economist & 1875 & 225 & 1650 \\
\hline 2. social security contributions & 721,50 & 66,30 & 655,20 \\
\hline 3. depreciation of fixed assets & & 2,10 & 35,71 \\
\hline software & 37,81 & 0,60 & 13,78 \\
\hline building & 14,38 & 2,74 & 30,19 \\
\hline office equipment & 32,93 & & 0,00 \\
\hline other & & 26,67 & 19,47 \\
\hline communication services & 26,67 & 2,33 & 2,08 \\
\hline electric power & 21,80 & 1,82 & 3276,43 \\
\hline paper & 3,9 & 357,56 & \\
\hline Total cost of solving a business problem & 3633,99 & & \\
\hline
\end{tabular}

Evaluation of the effectiveness of the implementation of the task implies the effectiveness of the automated transformation of economic information - the appropriateness of the use of computer technology in the formation, transmission and processing of information used. The stages of work on developing software for solving a business problem were identified. A cost estimate for the development of software for solving a business problem has also been compiled.

The cost of creating (purchasing) software is determined by the following costing items: material costs; labor costs; depreciation of fixed assets; other costs (communication services, electricity, etc.). 
Evaluation of the effectiveness of the implementation of the task implies the effectiveness of the automated transformation of financial information - the appropriateness of the use of computer technology in the formation, transmission and processing of information used (Kim et al., 2019 \& Dale et al., 2019).

We will calculate the economic efficiency of software development for solving a business problem on the basis of the «Cash Flow» method using the different approach.

To assess economic efficiency, we determined the net cash flow for 1 year, minus the cost of one-time investments and taking into account alternative missed opportunities. To assess the missed opportunities, we will take the Central Bank of the Russian Federation refinancing rate (12\%) as the comparison (discount) rate (Sapfirova et al., 2019).

\section{Results and Discussion}

The calculation of the economic efficiency of software development for solving a business problem was made on the basis of the «Cash Flow» method using the different approach.

To assess economic efficiency, net cash flow for 1 year was determined minus the cost of one-time investments and taking into account alternative missed opportunities. To assess missed opportunities, the Central Bank of the Russian Federation refinancing rate (12\%) was adopted as the comparison (discount) rate.

The basic indicators characterizing the economic efficiency and effect of this project are calculated: the net present value of the project; internal rate of return for a project; return on investment index; payback period of investments (simple and discounted).

The effectiveness of the implementation of the task «Distribution of orders by teams» was assessed: the annual economic effect of the implementation is 2237.03 rub.; the cost of developing a software product - 25715,40 rub.; discounted payback period is 11 months.

The managerial effect is achieved due to the fact that the time for receiving and distributing orders, as well as receiving operational information from them, is significantly reduced, and the quality of processing information and documents is improved. The economic effect is achieved by reducing the time for processing information on orders and the distribution of teams. For the free time, the person performing this task can be assigned other tasks.

\section{Summary}

Any enterprise is considered as a system of interacting processes. In the process of reengineering, the following business processes were identified: production preparation, main production, logistics, finance, accounting, transportation, repair support, staffing, social security, core business support, information support, management (management).

Based on business processes, an analysis of the structural divisions of the enterprise information system is made.

List of enterprise subsystems: technical and economic planning; primary production; material and technical support; Accounting; finance; transport support; repair support; provision of labor resources; provision of core business.

The paper presents an estimate of the costs of developing software for solving a business problem. The cost of creating (purchasing) software is determined by the following costing items: material costs; labor costs; depreciation of fixed assets; other costs (communication services, electricity, etc.).

Evaluation of the effectiveness of the implementation of the task implies the effectiveness of the automated transformation of economic information - the appropriateness of the use of computer technology in the formation, transmission and processing of information used.

The calculation of the economic efficiency of software development for solving a business problem was made on the basis of the «Cash Flow» method using the difference approach.

To assess economic efficiency, net cash flow for 1 year was determined minus the cost of one-time investments and taking into account alternative missed opportunities. To assess missed opportunities, the Central Bank of the Russian Federation refinancing rate (12\%) was adopted as a comparison (discount) rate.

\section{Conclusions}

Based on the survey, the most acceptable system was 1C: Accounting for the studied enterprise in the construction industry. This system is also valid for most medium-sized Russian enterprises.

For all business processes, business tasks were allocated. All tasks of business processes are interconnected on a timeline and on object flows. In order to show this connection, organizational - logical schemes were built. 
The process-task technology for managing business processes is based on a product model for organizing business processes. The main control element, in this case, is the business task and the products of its solution. The chief purpose of the enterprise management standard is to develop a technology to manage enterprise business processes.

The study aims to achieve economic and managerial efficiency at the enterprise of the road construction industry using modern information technologies.

The peculiarity of the enterprise analysis is that it enables you to observe the whole set of operations taking place in the enterprise. Moreover, it permits you to achieve the maximum managerial and economic efficiency of each of them. The process approach to managing the organization is oriented, first of all, not to the organizational structure of the enterprise, but to business processes, the ultimate goals of which are to create products or services of value to external or internal consumers.

The business process «Technical and Economic Planning», which is a subprocess of «Production Preparation», was considered. Based on the analysis of the «Feasibility Study» business process, the tasks of this process and their relationship are identified.

The primary toolkit for improving the business process, «Technical and Economic Planning,» is the information system. Based on the analysis of the existing enterprise information system, unrealized tasks were identified. This task includes the task «Distribution of orders by teams».

An information system was designed based on the business processes of the enterprise. The scheme of the information system with an indication of information flows is built.

A subsystem of «Technical and Economic Planning» was designed. With an indication of the tasks of the subsystem and the functions of the tasks, a diagram of the connection of the tasks of this subsystem with the tasks of other subsystems was constructed. The task «Distribution of orders by teams» was developed and implemented as a software product in the $1 \mathrm{C}$ programming environment.

The main issues of ensuring the information security of enterprises, as well as the direction of the formation of a system of protection of information resources, especially of limited access resources, are considered.

The effectiveness of the implementation of the task «Distribution of orders by teams» was assessed: the annual economic effect of the implementation is 2237.03 rub; the cost of developing a software product -25715.40 rub; discounted payback period is 11 months.

The managerial effect is achieved because the time for receiving and distributing orders, as well as receiving operational information from them, is significantly reduced, and the quality of processing information and documents is improved. The economic effect is achieved by reducing the time for processing information on orders and the distribution of teams. For the free time, the person performing this task can be assigned other tasks.

\section{Acknowledgements}

The work is performed according to the Russian Government Program of Competitive Growth of Kazan Federal University.

\section{References}

Albertovna, G., \& Grigoreva, D. R. (2016). Comprehensive Assessment of the reliability of the bank with the application of statistical methods. Academy of Strategic Management Journal, 15, 28.

Barsukov, V. (1997). Physical protection of information systems. Retrieved from http://www.jetinfo.ru/1997/1/1/article1.1.1997.html

Dale, A. M., Enke, C., Buckner-Petty, S., Hipp, J. A., Marx, C., Strickland, J., \& Evanoff, B. (2019). Availability and use of workplace supports for health promotion among employees of small and large businesses. American Journal of Health Promotion, 33(1), 30-38.

Falko, S. G., \& Berzin, I. E. (2012). Business Economics: Textbook. Moscow.

Gareeva, G., Grigoreva, D., \& Lysanov, D. (2016). Forecasting techniques in the research rail market.

Grigoreva, D. R., Faizullina, A. G., Basyrov, R. R., \& Sharipov, R. S. (2015). Use of Steiner problem in solving practical problems of road construction. Modern Applied Science, 9(4), 294.

Ivanov, F., \& Zyablov, V. (2013). Low-Density Parity-Check Codes Based on Steiner Triple Systems and Permutation Matrices. Proc. of 36th conference "Information technologies and systems (ITAS)". Kaliningrad, Russia. 
Kim, D., Park, K., Park, Y., \& Ahn, J. H. (2019). Willingness to provide personal information: Perspective of privacy calculus in IoT services. Computers in Human Behavior, 92, 273-281.

Lisin, A., \& Faizullin, R. (2013). The heuristic search algorithm for the approximate solution of the Steiner problem is based on physical analogies. Computer Optics, 4(37), 503-507.

Radchenko, M. G. (2013). Developer's practical guide (p. 512).

Sapfirova, A. A., Volkova, V. V., \& Petrushkina, A. V. (2017, December). Information technologies and information compliance in labor relations: Legal regulation and prevention of violations of labor rights. In Perspectives on the use of New Information and Communication Technology (ICT) in the Modern Economy (pp. 911-916). Springer, Cham.

\section{Copyrights}

Copyright for this article is retained by the author(s), with first publication rights granted to the journal.

This is an open-access article distributed under the terms and conditions of the Creative Commons Attribution license (http://creativecommons.org/licenses/by/4.0/). 